\title{
Developing A Revitalization Planning and Design Guideline for Enhancing Land Use Performance of a Shrinking City
}

\author{
Shu Yang, Jun-Hyun Kim*, Wonmin Sohn, and Zeenat Kotval-K \\ School of Planning, Design and Construction, Michigan State University, East Lansing 48824, USA
}

\section{ABSTRACT}

Background and objective: Land vacancy is a persistent issue in most urban areas in the United States, yet few case studies have examined how vacant lots are used and the functions they serve in local communities. The purposes of this study were to provide a new revitalization planning and design proposal for the Durant-Tuuri-Mott (DTM) target area in the shrinking city of Flint, MI, USA, and to assess the final planning and design guideline through an analysis of vacant land redevelopment alternatives.

Methods: For developing a revitalization planning and design guideline, this study developed several design modules with three main design themes. Then, landscape performance of the final design proposals was analyzed by three development scenarios, based on implementation level: 100\%, 75\%, and 50\%. These development scenarios were based on the local context and different implementation budgets needed to adopt the proposed design modules. To generate a comprehensive development plan by optimizing design module allocation in the study area, this research employed a system-oriented approach, analyzing the existing cultural, natural, and built environments. A community participant process was adopted to collect stakeholders' opinions on future development.

Results: By utilizing landscape performance metrics to quantify the environmental, social, and economic benefits, this study developed optimized development scenarios and a master plan for the reuse and redevelopment of existing vacant lots across DTM neighborhoods and analyzed the benefits of each.

Conclusion: This research offers a flexible design method for balancing objectives in vacant land redevelopment that can be applied in other shrinking cities.

Keywords: community participation, landscape performance, urban design, urban regeneration, vacant land

\section{Introduction}

Urban vacancy has become a significant and ubiquitous phenomenon in the United States. This is especially true in the Rust Belt region in the US, which includes Illinois, Indiana, Michigan, New Jersey, New York, Ohio, Pennsylvania, and West Virginia (Gu et al., 2019; Park et al., 2017). Vacant areas pose a security risk to cities (Garvin et al., 2013). Many urban areas located in the Rust Belt are se- verely impacted by this problem (Gu et al., 2019). Due to workforce relocation, deindustrialization, and suburban expansion, the number of vacant lots continues to increase. Detroit, MI, Cleveland, OH, and Philadelphia, PA, are examples of cities experiencing a significant population decline. Numerous studies have examined this trend of decline and explored how to revitalize these areas, showing that systematic and comprehensive regional planning is one of most effective solutions to address the particular issue of

This research was supported by the Genesee County Land Bank Authority (GCLBA) in Flint, MI and the Sustainable Built Environment Initiative (SBEI) led by Professor Wayne Beyea at Michigan State University (MSU). SBEI helped with survey data collection from community meetings. The authors thank MSU students Matthew Dikeman, Annabelle Wilkinson, and Elena Cangelosi for their assistance with data collection and support. Received: June 11, 2020, Revised: July 14, 2020, Accepted: July 23, 2020

First author: Shu Yang, yangshu8@msu.edu, (D) https://orcid.org/0000-0002-6183-3511

*Corresponding author: Jun-Hyun Kim, junhkim@msu.edu, (iD) https://orcid.org/0000-0002-3013-2579 
vacant lots in urban areas (Newman et al., 2016).

As one of these Rust Belt cities, the City of Flint in Michigan, USA has struggled with a number of environmental, social, and economic challenges in the past several decades. The city once thrived as the home of the nation's largest General Motors (GM) plant. However, since the 1980s, due to reductions in GM's workforce, the city's economy declined sharply (Scorsone, 2011). Increasing vacancy is currently one of the biggest challenges Flint faces. According to the Genesee County Land Bank Authority (GCLBA), the demolitions completed from 2001 to 2018 totaled 6,599 properties. By 2017, there were approximately 24,000 vacant properties in Flint, $42 \%$ of the city's property. Demolition consumes a vast portion of the city's resources. From 2015 to 2020 , the cost of these demolitions was estimated at USD\$71.88 million (City of Flint, 2018). Vacant lots often create space for unwanted vegetation and trash, inviting illegal activity and increasing violent crime (Garvin et al., 2013). Vacant lots also cause separation among residents, disconnecting neighborhoods from thriving areas of the city. Maintenance costs substantially increase when illegal dumping makes vacant lots unsafe. Moreover, redevelopment is a contested issue in many US cities; while residents desire more greenspace or public parks, municipal governments often prefer to utilize these lots in ways that generate tax revenue (Pearsall et al., 2014).

Redevelopment and management plans for revitalizing these declining cities are urgently needed (Gu et al., 2019). Creating a well-designed built environment is an effective way of mitigating the safety problems stemming from vacant lots and improving environmental, social and economic values of the community (Kim et al., 2015; Kim et al., 2017). One study in Philadelphia tested whether greening could reduce violent crime (Garvin et al., 2013), finding that it increased perceptions of safety. A number of previous studies have documented the positive impacts of greenspace, providing environmental (Park et al., 2017; Sohn et al., 2019), socioeconomic (Kim et al., 2018), and public health (Kim et al., 2014; Kim et al., 2016) benefits to communities. One study exploring if greening interventions had an impact on the mental health of community-dwelling adults in Philadelphia demonstrated that for residents living in neighborhoods below the poverty line, greening interventions led to significant decreases in depression (South et al., 2018). Also, Pearsall et al. (2014) highlighted the importance of greenspace for future community development, using a spatial analytical model to document the conversion of existing vacant lots to greenspace.

While vacant lots negatively influence cities, they also offer residents the opportunity to enjoy outdoor activities, interact with other community members, and restore physical and mental health in greenspaces. In Flint, the GCLBA adopted three stages of management - maintenance, improvement of amenities options, and ecological land use design - to plan for the development of vacant lots (City of Flint, 2018). However, a community master plan based on systematic planning and design guidelines has yet to be established. In addition, no effort has been made to assess the impact of future development in a way that considers the diverse environmental, social, and economic factors affecting the area.

The primary goals of this research are 1) to create and develop a design guideline for revitalizing a community in decline, applying a system-oriented design approach that uses a series of design modules for placemaking and 2) quantitatively assesses design performance with different development scenarios. This study proposes several design modules that address future implementation and maintenance costs, land uses, and resulting benefits from which planners and policy makers may choose.

\section{Research Methods}

\section{Study area}

Located at the edge of downtown, the Durant-Tuuri-Mott (DTM) target area is a 161.4-acre neighborhood in Flint, MI. The current site condition presents severe issues related to neighborhood vacancy with over 30\% vacant lots (Figs. 1 and 2). Flint's early rapid expansion was facilitated by its proximity to water and highway networks, making it easily accessible by car. The surrounding neighborhoods, including those in which Kettering University and Hurley Hospital are located, are major stakeholders in the DTM area, and these stakeholders own some of the vacant parcels 


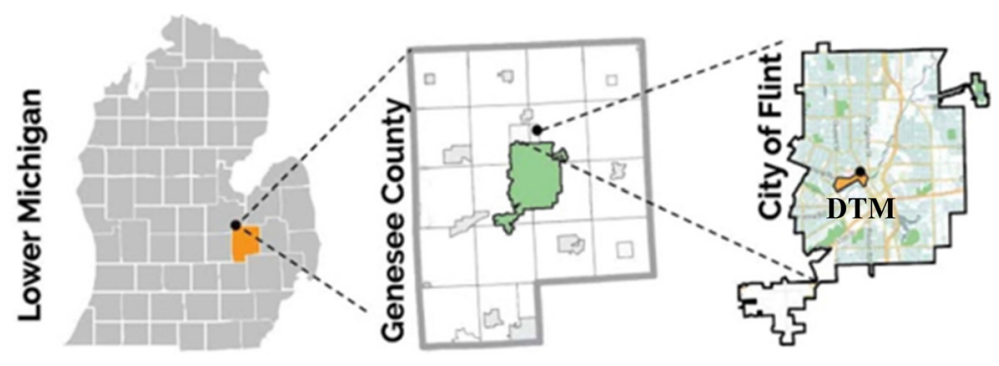

Fig. 1. Location of the study area.

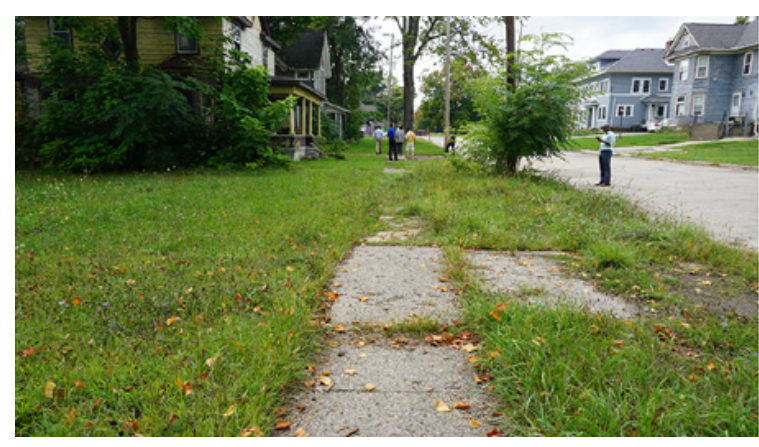

Fig. 2. Existing site conditions of vacant lots.

and land onsite. The target area has the potential to be redeveloped, with large amounts of existing open space, a good location and level of accessibility, and passionate residents and local organizations who are willing to participate in the community revitalization plan.

While vacant lots comprise $31.09 \%$ of the study area. The rest of the site is mainly multi-family residential $(25.04 \%)$, education (16.84\%), single-family residential (11.82\%), and other use including parking, retail and office, and religious or medical facilities. The high vacancy rate disconnects the neighborhood from the surrounding area, causing a loss of a sense of community. The substantial number of vacant lots have also led to an increase in crime (Garvin et al., 2013). Existing bike trails and bus routes provide access to surrounding facilities, neighborhoods, and the downtown. The sidewalks exist across the study area; however, a lack of pruning and general maintenance has made the sidewalks in the neighborhood unwalkable, especially for the elderly and disabled.

\section{Design guideline development process}

Several steps were involved in the decision-making proc-

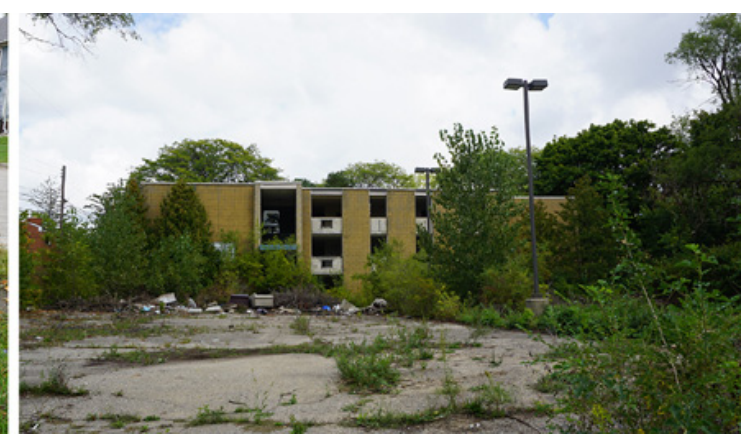

ess for developing the final master plan. Then, several landscape metrics were applied to quantify the benefits of the design proposal, focusing on environmental, social, and economic aspects (Fig. 3).

\section{Community participation in the decision-making process}

To collect community members' feedback on the present and future statuses of the DTM neighborhood, this study adopted a community participation decision-making process. Among two community meetings to collect feedback, 20 community members participated in the first community meeting held in November 2019, and shared their opinions with a short survey asking three open-ended questions, which has been developed by the Sustainable Built Environment Initiative (SBEI) at Michigan State University (Table 1). Each participant could answer multiple answers for each survey question. Thus, the final numbers of answers from each question were 86, 77, and 98, respectively. Data collection was completed by SBEI; a content analysis based on responses made during community meetings was then performed for this research. For the content analysis, we 


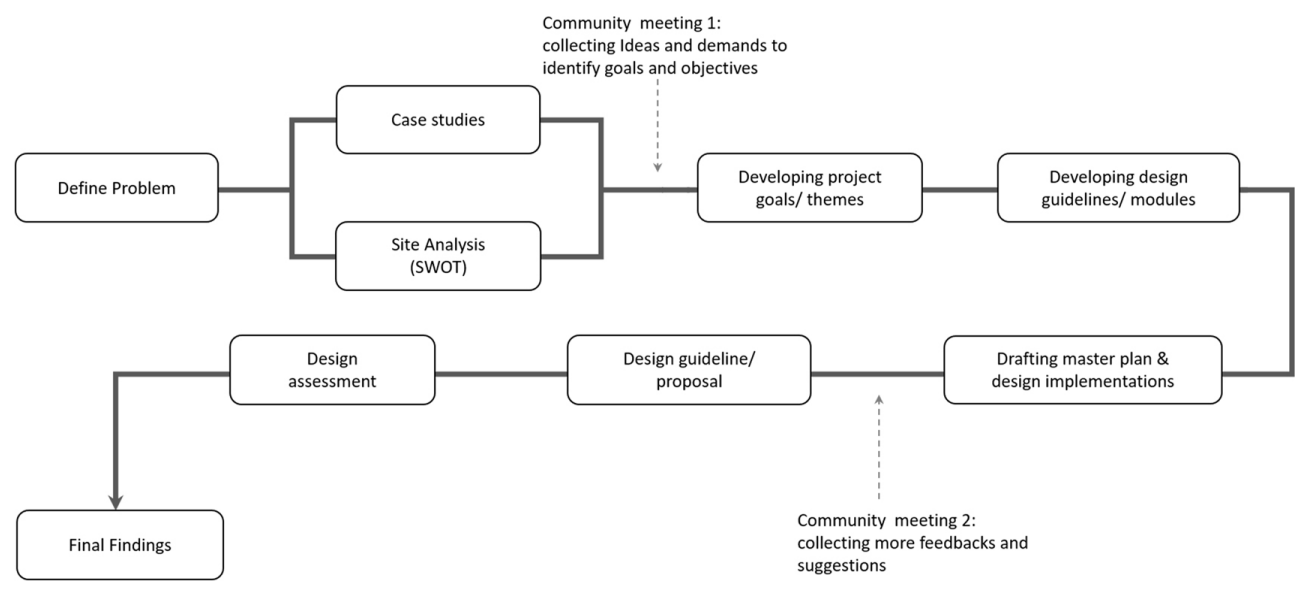

Fig. 3. Sequential framework for design guideline development.

Table 1. Community feedback

\begin{tabular}{|c|c|c|}
\hline Question & Feedback & Frequency $(\%)$ \\
\hline \multirow{7}{*}{$\begin{array}{l}\text { Q1: What are you most proud of about the } \\
\text { project site/immediate area? }(\mathrm{n}=86)\end{array}$} & Rehab work and development in neighborhood & $22(25.6 \%)$ \\
\hline & Community engagement activities & $21(24.4 \%)$ \\
\hline & Existing facilities (Atwood Stadium, Educare, etc.) & $15(17.4 \%)$ \\
\hline & Connectivity (bike paths, trails, walkability) & $9(10.4 \%)$ \\
\hline & Businesses & $6(7.0 \%)$ \\
\hline & Rich history \& legacy & $2(2.3 \%)$ \\
\hline & Other & $11(12.8 \%)$ \\
\hline \multirow{8}{*}{$\begin{array}{l}\text { Q2: What are you most dissatisfied with } \\
\text { regarding the project site and } \\
\text { immediate area? }(\mathrm{n}=77)\end{array}$} & Blighted \& abandoned properties & $16(20.8 \%)$ \\
\hline & Insufficient number of businesses & $15(19.5 \%)$ \\
\hline & Sidewalk conditions & $11(14.3 \%)$ \\
\hline & No place to live & $9(11.7 \%)$ \\
\hline & Lack of safety & $8(10.4 \%)$ \\
\hline & Loss of identity & $6(7.8 \%)$ \\
\hline & Public open spaces & $4(5.2 \%)$ \\
\hline & Other & $8(10.4 \%)$ \\
\hline \multirow{9}{*}{$\begin{array}{l}\text { Q3: If you could float over the site in a } \\
\text { hot air balloon } 15 \text { years from now, } \\
\text { what would you most like to see? } \\
(\mathrm{n}=98)\end{array}$} & Community diversity & $18(18.4 \%)$ \\
\hline & High-quality outdoor spaces & $17(17.3 \%)$ \\
\hline & Redevelopment & $15(15.3 \%)$ \\
\hline & Bikeability \& walkability & $12(12.2 \%)$ \\
\hline & Connectivity & $10(10.2 \%)$ \\
\hline & Businesses & $10(10.2 \%)$ \\
\hline & More greenspace & $5(5.1 \%)$ \\
\hline & Safety & $3(3.1 \%)$ \\
\hline & Other & $8(8.2 \%)$ \\
\hline
\end{tabular}

analyzed the presence and meanings of participants' responses from the open-ended questions by categorizing their answers in similar groups to quantify frequency counts.
Based on the survey results, $25.6 \%$ claimed that they were proud of the current rehabilitation work in and development of the neighborhood, and $24.4 \%$ and $17.4 \%$ said 


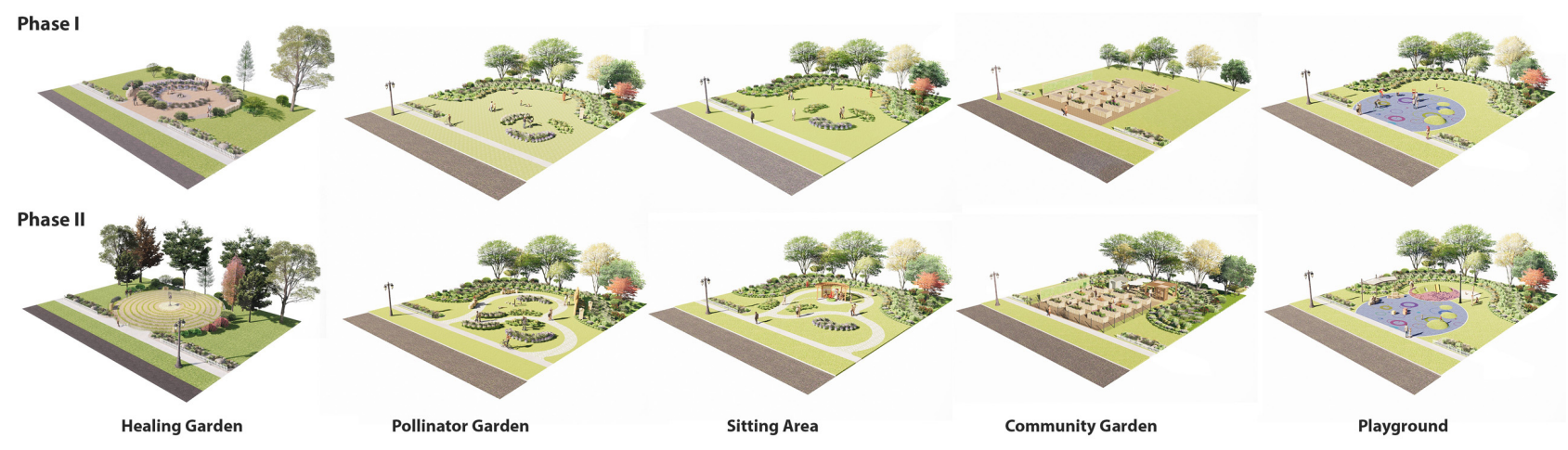

Fig. 4. Design modules for Theme 1: enhancing vacant lots in residential areas.

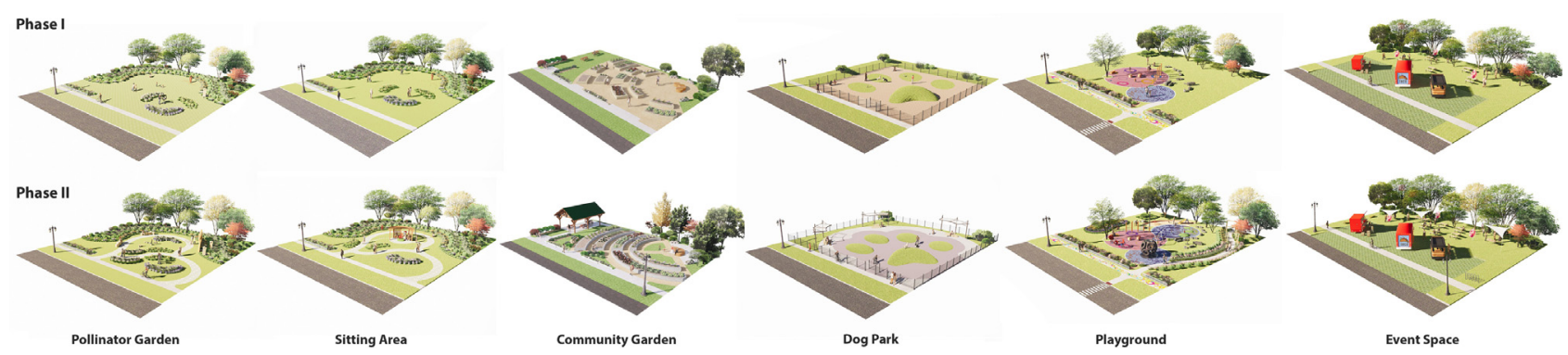

Fig. 5. Design modules for Theme 2: creating public open space.

that they were proud of community engagement activities and existing facilities, respectively. A total of $10.4 \%$ were satisfied with the connectivity of the existing bike paths, trails, and sidewalks. For elements generating dissatisfaction, community members described blighted and abandoned properties (20.8\%), an insufficient number of businesses (19.5\%), and existing sidewalk conditions (14.3\%). Regarding what community members wished to see in the next 15 years, $18.4 \%$ wanted more community diversity, while $17.3 \%$ and $15.3 \%$ looked forward to high-quality outdoor spaces and redevelopment, respectively.

\section{Establishing design goals and modules}

Based on feedback gathered during community meetings and a site analysis, this project set four major goals: 1) revitalization in terms of site positioning and optimizing the potential value of vacant lots to improve residents' quality of life; 2) placemaking to explore the features of existing conditions, maximizing function of the site for residents while promoting social engagement, health and safety and enhancing a sense community; 3) connectivity to fill gaps caused by vacant parcels by increasing the connectivity of the space on both site and city levels; and 4) sustainability to promote green development by incorporating ecological, social, and economic perspectives.

Due to the large size of the site and uncertainty of future development that each vacant lot contains, this project devised a series of design modules for three selected themes in developing a design guideline for vacant lot revitalization. Based on the main theme of each module, design modules present different sets of amenities such as sitting areas with benches and/or overhead structures, community gardens, pollinator gardens, gathering areas, playgrounds, and event places (Figs. 4 and 5). All design modules share common design considerations (e.g. public open space, safety features, sustainable design features such as rain gardens and bioswales, sidewalk enhancement, etc.) reflecting the major goals established for this project. To develop the master plan, three themes were determined based on land use types: 1) enhancing vacant lots in residential areas, 2) creating public open spaces, and 3) implementing mixed-use development. While Theme 1 focuses on small-scale vacant lots, Theme 2 considers the development of larger-scale 
vacant lots with more comprehensive amenities for surrounding residents. For Theme 3, this study identified several sites in commercial areas. For each theme, two sequential phases were developed to illustrate the site status at different implementation levels. The first phase applies a cost-benefit or tactical urbanism approach, including site cleaning and affordable amenities. The purpose of the first phase is to test if the module fits the site usage. Once the proposed idea for each initial site phase gathers community consensus regarding permanent development, the site enters the second phase. In the second phase, the design seeks to enhance a sense of place and ownership, promoting social interaction through community gatherings and events and encouraging careful stewardship. More amenities are added in this phase, such as shade trees and permanent structures. However, if after applying the first phase the proposed design modules are not aligned, new alternative design ideas can be explored. This study applied the second phase design solutions to quantify landscape performance analysis. The phasing plans for Theme 3 were determined based on development density and the characteristics of available lots that might make them a good fit for future mixed-use development. Since the project identified a few of specific sites for future mixed-use development in the study area based on the community meetings, a design module approach for Theme 3 was not developed.

\section{Development scenarios and master plans}

To quantify design impact, this study projected three development scenarios: $100 \%, 75 \%$, and $50 \%$ site development. This scenario-based approach serves to respect the community's future financial and social status and existing site conditions. The $100 \%$ development scenario assumes that the entire quantity of vacant lots in the study area is developed, while $75 \%$ and $50 \%$ development scenarios revitalize sites according to priority. The $75 \%$ development scenario is based on the prediction that $73.4 \%$ of the existing vacant lots will be developed, and the $50 \%$ development scenario is based on the existing vacancy conditions, in which approximately $46.7 \%$ of the existing vacant lots are redeveloped, with no existing structures on any of the lots (Table 2). Finally, three different master plans were proposed in accordance with the development scenarios (Fig. 6).

\section{Landscape performance measurement}

This study utilized several landscape performance metrics to quantify the future impacts of the design proposals. Landscape performance research has been applied widely to quantify the performance of built landscape projects. In the past ten years, the Landscape Architecture Foundation

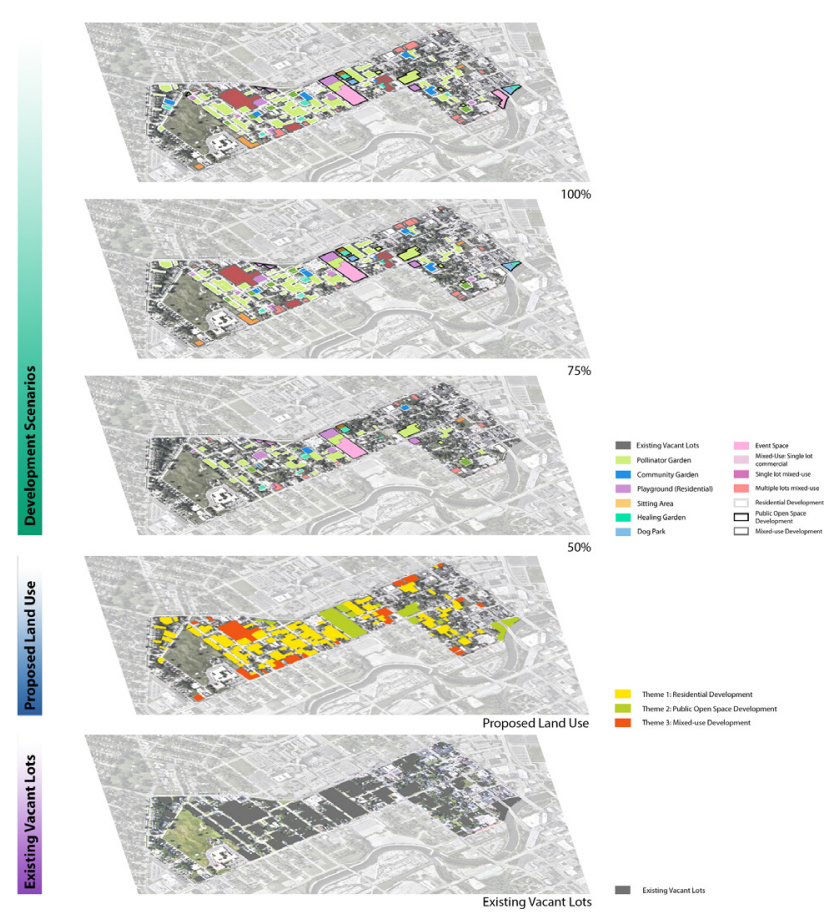

Fig. 6. Master plans and proposed land use.

Table 2. Proposed development areas by development scenario

\begin{tabular}{cccccc}
\hline $\begin{array}{c}\text { Development } \\
\text { scenario }\end{array}$ & $\begin{array}{c}\text { Existing vacant area } \\
\left(\mathrm{m}^{2}\right)\end{array}$ & $\begin{array}{c}\text { Estimated } \\
\text { developed area }\end{array}$ & $\begin{array}{c}\text { Theme 1 } \\
\left(\mathrm{m}^{2}\right)\end{array}$ & $\begin{array}{c}\text { Theme 2 } \\
\left(\mathrm{m}^{2}\right)\end{array}$ & $\begin{array}{c}\text { Theme 3 } \\
\left(\mathrm{m}^{2}\right)\end{array}$ \\
\hline $100 \%$ & & $100.0 \%$ & 101,246 & 39,097 & 39,169 \\
$75 \%$ & 179,511 & $73.4 \%$ & 74,314 & 28,697 & 28,750 \\
$50 \%$ & & $46.7 \%$ & 47,282 & 18,258 & 18,292 \\
\hline
\end{tabular}


(LAF) has produced over 150 case studies with the collaboration of faculty-student research teams, designers, and clients (LAF, 2018). Landscape performance research generally focuses on calculating the measurable benefits of a built landscape project, considering a number of environmental, social, and economic factors. For this study, several landscape performance metrics were selected to measure the benefits of the final design proposals according to environmental, social, and economic dimensions (Table 3). In addition, data availability and representation of values to interpolate the results were considered to select the final set of the landscape metrics. The selected environmental metrics focused on measuring the landscape performance of the proposed sustainable and low impact development (LID) features, including stormwater management via newly implemented rain gardens, bioswales, and permeable paving, and air quality enhancement from the proposed greenspace and tree canopy. The social benefits measured the performance of the proposed social interactive/gathering areas and safety enhancements, while rental income, community garden profits, tax revenue, and savings in terms of maintenance costs were selected to quantify the economic benefits.

\section{Results and Discussion}

\section{Environmental benefits}

As shown in Table 4, the annual $\mathrm{CO}_{2}$ sequestration will be $11,584 \mathrm{~kg}$ in the $100 \%$ development scenario and will be reduced to $8,688 \mathrm{~kg}$ and $5,792 \mathrm{~kg}$ in the $75 \%$ and $50 \%$ development scenarios, respectively. The benefits of annual air pollution removal in the $100 \%, 75 \%$, and $50 \%$ develop-

Table 3. Landscape performance metrics

\begin{tabular}{|c|c|c|c|}
\hline Metric & Variable & Data for measurement & Unit \\
\hline \multicolumn{4}{|l|}{ Environmental benefits } \\
\hline $\mathrm{CO}_{2}$ sequestration & Reduced amount of $\mathrm{CO}_{2}$ & Tree species, DBH (cm), land use, and height (m) & $\mathrm{kg} /$ year \\
\hline Air pollution removal & Cost savings from removing air pollution & Tree species, DBH $(\mathrm{cm})$, land use, and height $(\mathrm{m})$ & $\$ /$ year \\
\hline \multirow{5}{*}{$\begin{array}{l}\text { Stormwater runoff reduction } \\
\text { Groundwater recharge } \\
\text { increase }\end{array}$} & Groundwater recharge (infiltration) & \multirow{5}{*}{$\begin{array}{l}\text { Soil type and drainage, topography (slope), } \\
\text { precipitation, evaporation, land cover, and LID types }\end{array}$} & $\mathrm{cm} /$ year \\
\hline & Percent of wet days retained & & $\%$ \\
\hline & Least rainfall w/o runoff & & $\mathrm{cm}$ \\
\hline & Most rainfall w/o runoff & & $\mathrm{cm}$ \\
\hline & Maximum rainfall retained & & $\mathrm{cm}$ \\
\hline \multicolumn{4}{|l|}{ Social benefits } \\
\hline \multirow{3}{*}{ Capacity of gathering space } & Capacity of gathering space & $\begin{array}{l}\text { Area of proposed gathering space }\left(\mathrm{m}^{2}\right) / \\
\text { Space for each guest }\left(\mathrm{m}^{2} / \text { person }\right)\end{array}$ & person \\
\hline & Increased scenery space & Area of scenery space & $\mathrm{m}^{2}$ \\
\hline & Increased activity space & Area of activity space & $\mathrm{m}^{2}$ \\
\hline \multirow{3}{*}{ Safety enhancement } & Sidewalk maintenance & Length of sidewalks maintained & $\mathrm{m}$ \\
\hline & New sidewalks & Length of new sidewalks added & $\mathrm{m}$ \\
\hline & Number of crosswalks added & Number of pedestrian crossings added & EA \\
\hline \multicolumn{4}{|l|}{ Economic benefits } \\
\hline \multirow{2}{*}{ Rental income } & Increased apartment rental income & Apartment rent $\left(\$ / \mathrm{m}^{2} / \mathrm{month}\right)$ & $\$ /$ month \\
\hline & Increased retail rental income & Retail rent $\left(\$ / \mathrm{m}^{2} /\right.$ year $)$ & $\$ /$ year \\
\hline Community garden profits & Increased profit from community garden & Profit $(\$)$ per planting area $\left(\mathrm{m}^{2}\right)$ & $\$$ \\
\hline Projected tax revenue increase & Tax appraisal value & Retail tax revenue $\left(\$ / \mathrm{m}^{2} /\right.$ year $)$ & $\$ /$ year \\
\hline Maintenance cost reduction & Maintenance cost savings & $\begin{array}{l}\text { Cost maintenance for natural plants }(\$ / \mathrm{ha}) \text {, cost } \\
\text { maintenance for native plants }(\$ / \mathrm{ha}) \text {, planting area (ha) }\end{array}$ & $\$$ \\
\hline
\end{tabular}

Note. Sources: EPA National Stormwater Calculator; iTree Eco; LoopNet; Wisely (2016); Hahn (2016). 
Table 4. Environmental benefits

\begin{tabular}{llccc}
\hline \multicolumn{1}{c}{ Metric } & \multicolumn{1}{c}{ Variable } & $100 \%$ Scenario results & $75 \%$ Scenario results & $50 \%$ Scenario results \\
\hline $\mathrm{CO}_{2}$ sequestration & Reduced amount of $\mathrm{CO}_{2}$ & $11,584 \mathrm{~kg} /$ year & $8,688 \mathrm{~kg} /$ year & $5,792 \mathrm{~kg} /$ year \\
Air pollution removal & Cost savings from removing air pollution & $\$ 3,136.77 /$ year & $\$ 2,352.58 /$ year & $\$ 1,568.39 /$ year \\
\cline { 1 - 3 } & Groundwater recharge (infiltration) & $8,842 \mathrm{~cm} /$ year & $6,631 \mathrm{~cm} /$ year & $4,421 \mathrm{~cm} /$ year \\
Stormwater runoff & Percent of wet days retained & $85 \%$ & $63.75 \%$ & $42.50 \%$ \\
reduction and & Least rainfall w/runoff & $73.66 \mathrm{~cm}$ & $55.25 \mathrm{~cm}$ & $36.83 \mathrm{~cm}$ \\
groundwater recharge & Most rainfall w/o runoff & $508 \mathrm{~cm}$ & $381 \mathrm{~cm}$ & $254 \mathrm{~cm}$ \\
increase & Maximum rainfall retained & $541 \mathrm{~cm}$ & $405.8 \mathrm{~cm}$ & $270.5 \mathrm{~cm}$ \\
\hline
\end{tabular}

Table 5. Social benefits

\begin{tabular}{|c|c|c|c|c|}
\hline Metric & Variable & $100 \%$ Scenario results & $75 \%$ Scenario results & $50 \%$ Scenario results \\
\hline \multirow{3}{*}{ Capacity of gathering space } & Capacity of gathering space & 9,358 people & 6,704 people & 4,635 people \\
\hline & Increased scenery area & $48,702 \mathrm{~m}^{2}$ & $38,813 \mathrm{~m}^{2}$ & $26,135 \mathrm{~m}^{2}$ \\
\hline & Increased activity area & $91,641 \mathrm{~m}^{2}$ & $87,705 \mathrm{~m}^{2}$ & $67,302 \mathrm{~m}^{2}$ \\
\hline \multirow{3}{*}{ Safety enhancement } & Sidewalk maintenance & $3,620 \mathrm{~m}$ & $3,620 \mathrm{~m}$ & $3,620 \mathrm{~m}$ \\
\hline & New sidewalks & $991 \mathrm{~m}$ & $991 \mathrm{~m}$ & $991 \mathrm{~m}$ \\
\hline & Number of crosswalks added & $85 \mathrm{EA}$ & $85 \mathrm{EA}$ & $85 \mathrm{EA}$ \\
\hline
\end{tabular}

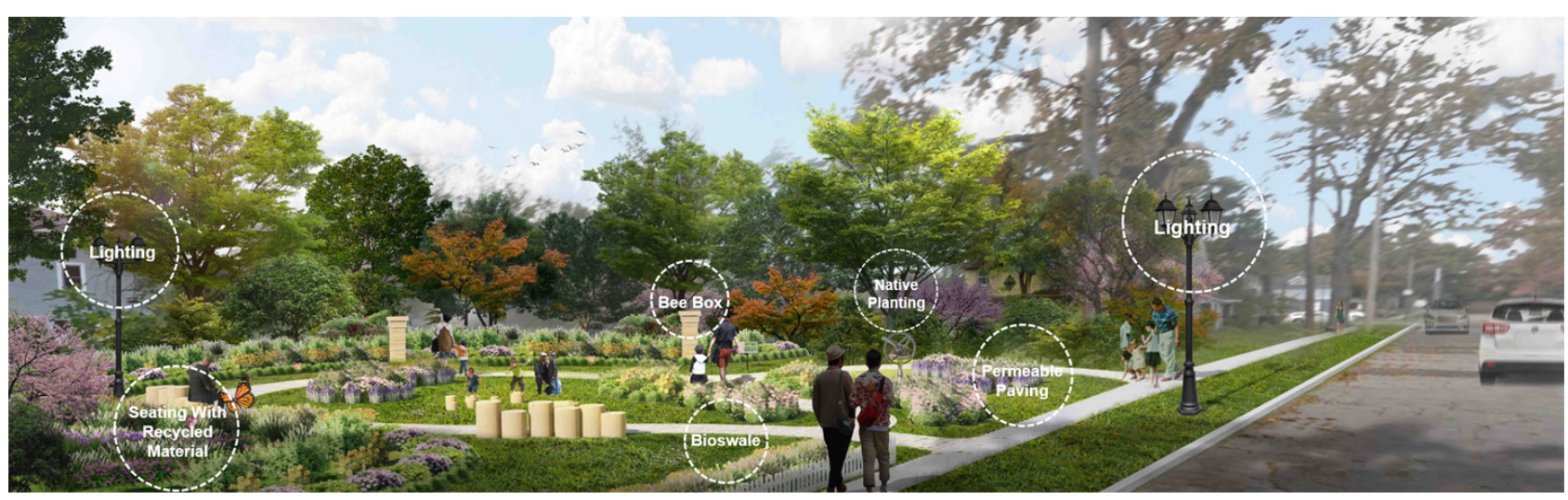

Fig. 7. Example of vacant lot design proposal in a residential area (pollinator garden module).

ment scenarios are $\$ 3,136.77, \$ 2,352.58$, and $\$ 1,568.39$, respectively. The design proposal represents a significant increase in annual groundwater recharge $(8,842 \mathrm{~cm}$ in the $100 \%$ development scenario, $6,631 \mathrm{~cm}$ in the $75 \%$ development scenario, and $4,421 \mathrm{~cm}$ in the $50 \%$ development scenario). The percentages of wet days retained are $85 \%, 63.75 \%$, and $42.5 \%$ in the $100 \%, 75 \%$, and $50 \%$ development scenarios, respectively. The maximum rainfall levels retained in the $100 \%, 75 \%$, and $50 \%$ development scenarios are $541 \mathrm{~cm}, 405.8 \mathrm{~cm}$, and $270.5 \mathrm{~cm}$, respectively (Fig. 7).

\section{Social benefits}

The social benefits were measured by six variables (Table 5). In the $100 \%$ development scenario, the new gathering space can accommodate 9,356 people, while 6,704 people and 4,635 people can gather in the open spaces proposed in the $75 \%$ and $50 \%$ development scenarios, respectively. The proposed scenery areas $\left(48,702 \mathrm{~m}^{2}\right.$ in the $100 \%$ development scenario, 38,813 in the $75 \%$ development scenario, and 26,135 in $50 \%$ development scenario) and activity areas $\left(91,641 \mathrm{~m}^{2}\right.$ in the $100 \%$ development scenario, 


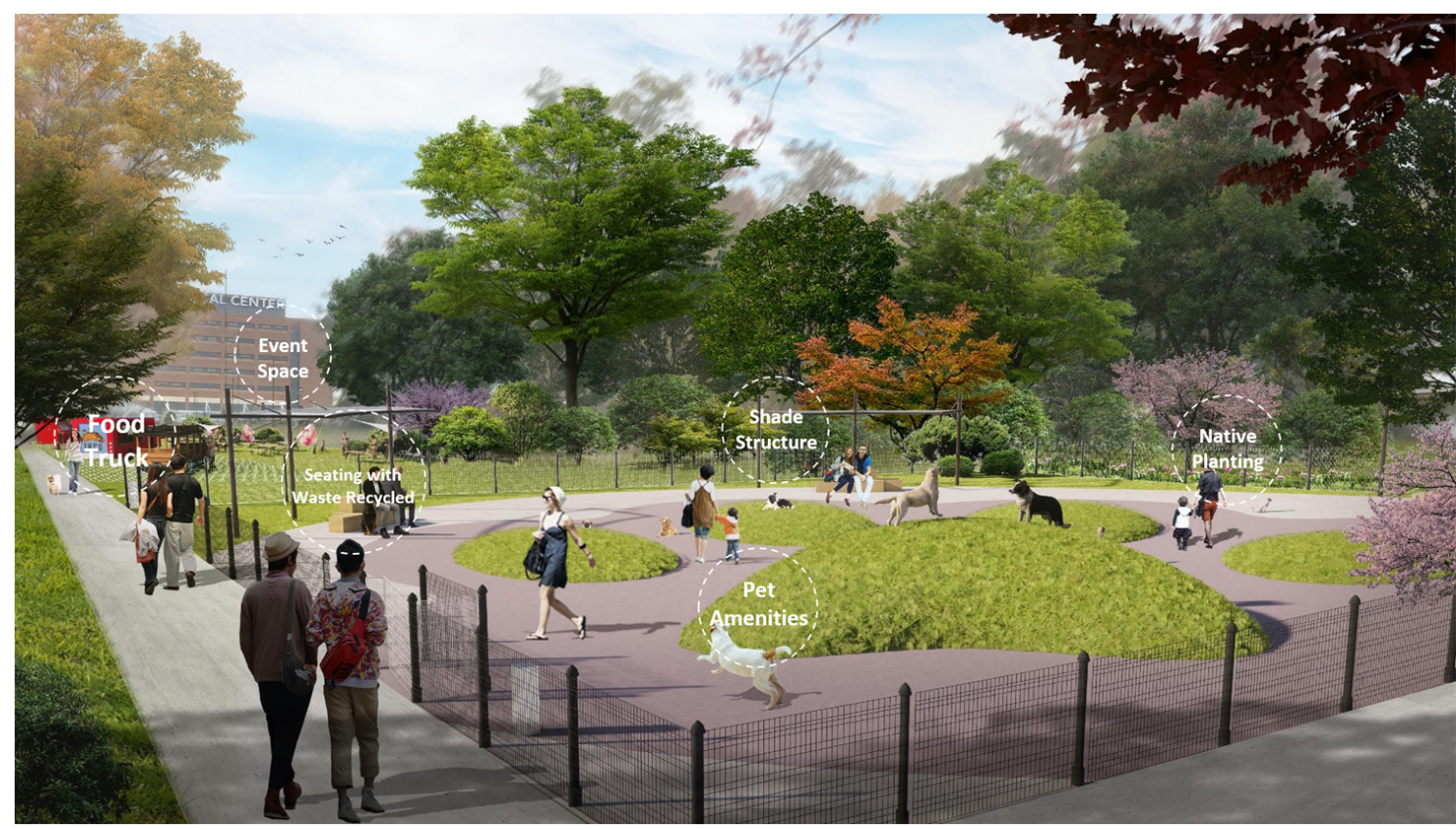

Fig. 8. Example of an open space design proposal (dog park and event space modules).

Table 6. Economic benefits

\begin{tabular}{llccc}
\hline \multicolumn{1}{c}{ Metric } & \multicolumn{1}{c}{ Variable } & $100 \%$ & $75 \%$ & $50 \%$ \\
& & Scenario results & Scenario results & Scenario results \\
\hline Rental income & Increased apartment rental income & $\$ 73,223 /$ month & $\$ 53,370.3 /$ month & $\$ 34,679.38 /$ month \\
& Increased retail rental income & $\$ 148,577 /$ month & $\$ 111,054 /$ month & $\$ 58,727 /$ month \\
Community garden profit & Increased profit from community garden & $\$ 68,038$ & $\$ 51,028$ & $\$ 34,019$ \\
Projected tax revenue increase & Tax appraisal value & $\$ 2,026,050 /$ year & $\$ 1,514,375 /$ year & $\$ 800,825 /$ year \\
Maintenance reduction & Maintenance cost savings & $\$ 40,970$ & $\$ 35,024$ & $\$ 28,370$ \\
\hline
\end{tabular}

$87,705 \mathrm{~m}^{2}$ in the $75 \%$ development scenario, and 67,302 in the $50 \%$ development scenario) are both significantly expanded (Fig. 8). To improve connectivity, 3,620 m of enhanced or $991 \mathrm{~m}$ of new sidewalks are offered and 85 crosswalks added in all three scenarios. The proposed new and existing sidewalks will bring benefits such as enhancing safety and moderating traffic accidents.

\section{Economic benefits}

The metrics selected for calculating the economic benefits included rental income, tax revenue increase, and maintenance cost reduction (Table 6). The results show that the community garden modules in the final design proposal can bring economic benefits of $\$ 68,038$ in the $100 \%$, $\$ 51,028$ in the $75 \%$, and $\$ 34,018$ in the $50 \%$ development scenarios. The total income from rent was the sum of the apartment and retail rental income. In the $100 \%$ development scenario, the apartment rent income can reach \$73,223/month; it yields $\$ 53,370.3 /$ month and $\$ 34,679.4 /$ month in the $75 \%$ and 50\% development scenarios, respectively (Figs. 9 and 10). Projected tax revenue from the proposed mixed-used development can yield \$2,026,050/year in the $100 \%$ development scenario, while producing \$1,514,375/year and $\$ 800,825 /$ year in the $75 \%$ and $50 \%$ development scenarios, respectively. The design proposal showed that even the $50 \%$ development scenario contributes to savings in maintenance costs of $\$ 28,370$ per year. If the $100 \%$ development scenario will be adopted, the maintenance cost savings can increase up to $\$ 40,970$ per year. In addition, the sidewalks maintained and new crosswalks proposed save vehicle gas costs and offer health benefits. According to the Economic 


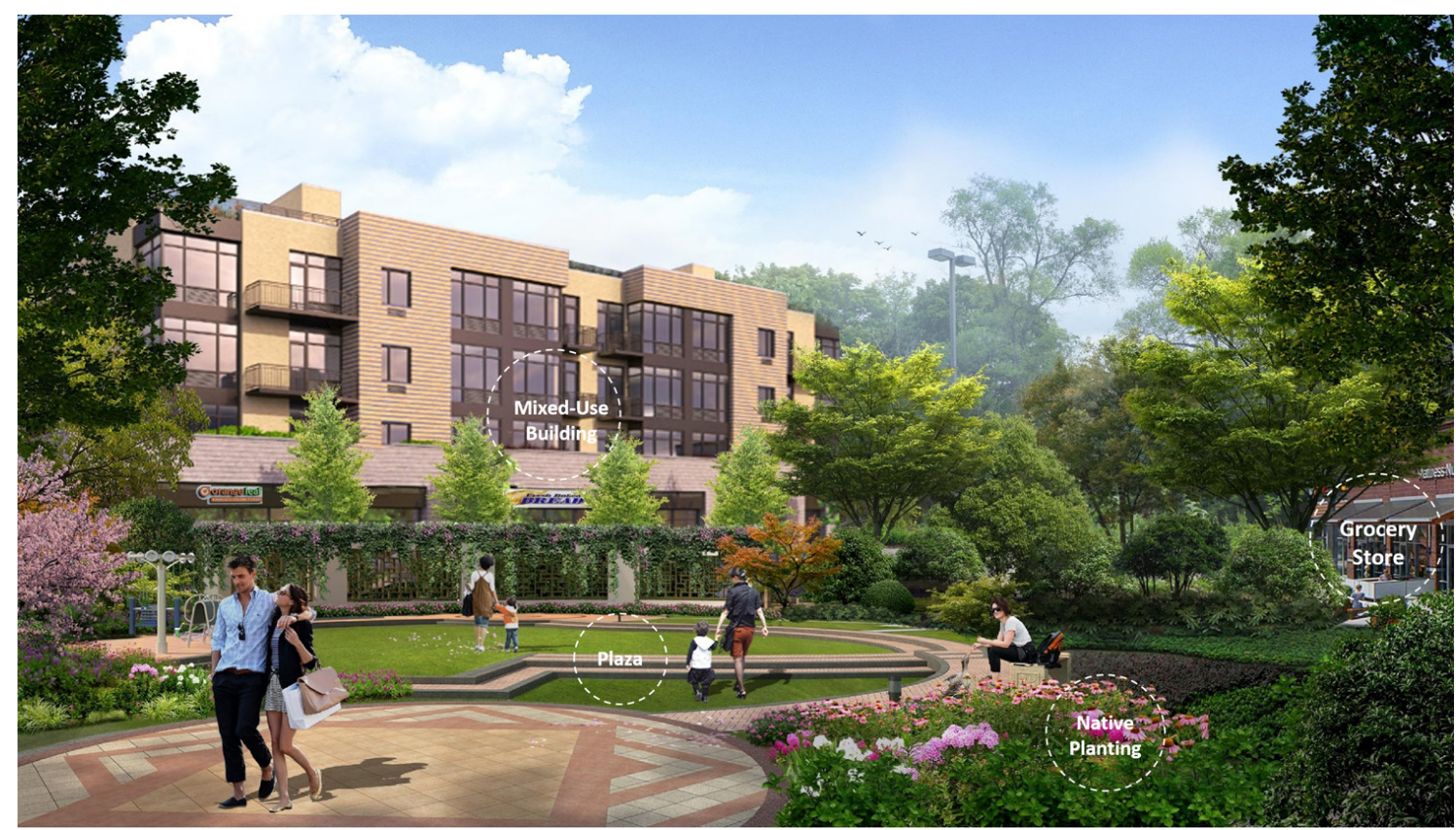

Fig. 9. Example of a mixed-use development proposal (high density: 100\% development scenario).

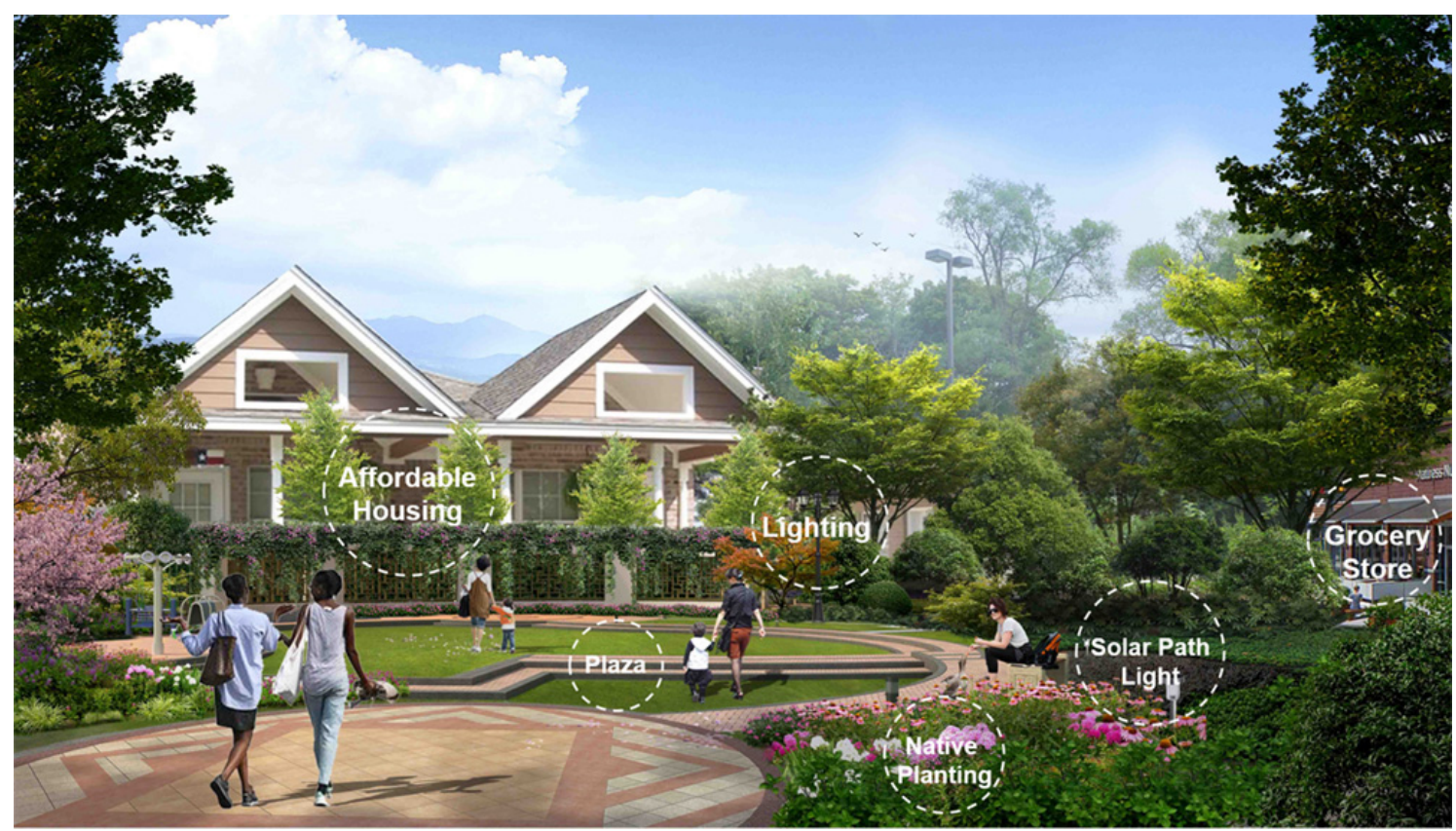

Fig. 10. Example of a mixed-use development proposal (low density: $50 \%$ development scenario).

Value of Walkability report, shifting from driving to walking can save gas costs of $\$ 0.25$ per vehicle-mile. Under peak urban conditions, $\$ 0.50$ per vehicle-mile can be saved. In terms of health, walking can bring $\$ 0.48$ per mile benefits by reducing hospital costs (Litman, 2003).

\section{Conclusion}

In recent years, urban vacancy has become a common issue in city development around the world. It is often the result of deindustrialization, workforce relocation, and suburban expansion (Kremer et al., 2013). The over-expansion 
of cities is likely to cause the most decline in urban cores (Newman et al., 2016). Planners, designers, and policy makers have conducted studies examining typical cities in decline in the United States, describing the physical environment and related socio-economic challenges. Case studies on sustainable practices applied in vacant lots also serve as valuable reference materials. The study site for the present research, the DTM target area in Flint, MI, would benefit from an examination of previous efforts as it confronts its current land vacancy problems.

The goal of this study was to propose a comprehensive master plan for optimizing revitalization of the target area, providing different development scenarios with a design guideline and quantitatively measuring the expected benefits via landscape performance metrics. This study employed several design modules to optimize application of different design solutions by analyzing the surrounding land use in ways that reflected community members' feedback in a comprehensive community participatory decision-making process. The final design proposal includes three development scenarios organized according to the projected development area: $100 \%, 75 \%$, and 50\%. In each scenario, the final design guidelines reinforce three main themes: 1) enhancing vacant lots in residential areas, 2) creating new public open spaces, and 3) implementing mixed-use development. For Themes 1 and 2, 11 design modules were developed based on onsite analysis, community feedback, and case study. The development scenarios for Theme 3 (i.e., mixed-use development) were based on the different densities of new developments proposed for specific commercial lots within the study area.

To quantify the benefits of the propose design, landscape performance research was conducted focusing on three primary dimensions: environmental, social, and economic benefits. Through newly proposed greenspaces and diverse design modules, in the $100 \%$ development scenario, the proposed design will contribute to enhancing environmental quality by reducing stormwater runoff $(1,370 \mathrm{~cm} / \mathrm{year})$, improving $\mathrm{CO}_{2}$ sequestration (11,584 $\mathrm{kg} /$ year), and removing air pollution (\$3,631.77/year). To enhance the sense of community, the design proposal offers several social benefits by providing more gathering space and community gardens, which offer residents increased opportunities to inter- act with their fellow community members. To address safety concerns, proposed traffic-calming devices, new or enhanced sidewalks, and well-maintained infrastructure will encourage people to engage in outdoor activities both safely and comfortably. In terms of economic benefits, increases in rental income and tax revenue and reductions in maintenance costs will significantly improve economic revenue.

However, this study has limitations. First, landscape performance research is more accurate when a built project is evaluated; the benefits of the proposed design proposal in this study are estimated based on a simulation approach. Second, the project does not draw comparisons with a baseline scenario of no development, since the comprehensive baseline scenario data are not available. Finally, due to the uncertain future development of the community, varying interests of multiple stakeholders, and challenges affecting the potential budget, the development scenarios used in this study may not be feasible for implementation in the near future.

Despite these limitations, following the proposed design guideline would allow this neighborhood to develop highperforming place in the community and transform a neglected area into a safe, healthy, and welcoming space. Future studies could engage more design module options and draw additional connections between modules, considering the site context, development pace, and level of economic growth. Developing design modules according to various scenarios allows for more flexible development options for residents; these modules can then be used as a reference for the redesign of large-scale vacant lots in years to come. The impacts of the project as calculated by landscape performance metrics will contribute not only to the neighborhood's future development, but expand outward into the entire city of Flint and other struggling areas that face similar vacancy problems. The developed design guideline also provides potential benefits and design impacts that can be considered at an early stage of design processes when prioritizing choices during the decision-making process.

\section{References}

City of Flint. 2018. 2017 Vacant property maintenance plan. Retrieved from https://www.cityofflint.com/wp-content/ 
uploads/Vacant-Properties-Maintenance-Plan-2017.pdf

Garvin, E.C., C.C. Cannuscio, and C.C. Branas. 2013. Greening vacant lots to reduce violent crime: A randomised controlled trial. Inj. Prev. 19(3):198-203. https://doi.org/ 10.1136/injuryprev-2012-040439

Gu, D., G. Newman, J.H. Kim, Y. Park, and J. Lee. 2019. Neighborhood decline and mixed land uses: Mitigating housing abandonment in shrinking cities. Land Use Policy 83:505-511. https://doi.org/10.1016/j.landusepol. 2019.02.033

Hahn, H. 2016. 2016 Case Study Investigation: EPA Region 7 Headquarters. Landscape Performance Series:1-38. Retrieved from https:/www.landscapeperformance.org/ sites/default/files/EPA Region 7 HQ Methods Document _0.pdf

Kim, J.H., C. Lee, N.E. Olvera, and C.D. Ellis. 2014. The role of landscape spatial patterns on obesity in Hispanic children residing in inner-city neighborhoods. J. Phys. Act. Health 11(8):1449-1457. https://doi.org/10.1123/jp ah.2012-0503

Kim, J.H., C. Lee, and W. Sohn. 2016. Urban natural environments, obesity, and health-related quality of life among hispanic children living in Inner-City neighborhoods. Int. J. Environ. Res. Public Health 13, 121. https://doi.org/1 $0.3390 /$ ijerph13010121

Kim, J.H., W. Li, G. Newman, S.H. Kil, and S.Y. Park. 2018. The influence of urban landscape spatial patterns on single-family housing prices. Environ. Plan. B Urban Anal. City Sci. 45(1):26-43. https://doi.org/10.1177/026 5813516663932

Kim, J.H., G. Newman, H. Feng, J. Merrill, J. Park, and J. Bian. 2017. Sustainable urbanism for a metropolitan corridor: An evidence-based urban design for Park 10 in Houston, Texas. Landsc. Archit. Front. 5(5):96. https://doi.org/10.15302/j-laf-20170510

Kim, J.H., S. Ning, W. Sohn, G. Newman, and M. Thomas. 2015. The energy corridor district comprehensive master plan, Houston, Texas, USA. Landsc. Archit. Front. 3(5):82-97.

Kremer, P., Z.A. Hamstead, and T. McPhearson. 2013. A social-ecological assessment of vacant lots in New York
City. Landsc. Urban Plan. 120:218-233. https://doi.org/1 0.1016/j.landurbplan.2013.05.003

Landscape Architecture Foundation. 2018. Evaluating landscape performance: A guidebook for metrics and methods selection. Washington, DC: Author.

Litman, T. 2003. Economic value of walkability. Transp. Res. Rec. 1828(1):3-11. https://doi.org/10.3141/1828-01

Newman, G., D. Gu, J.H. Kim, A.O.M. Bowman, and W. Li. 2016. Elasticity and urban vacancy: A longitudinal comparison of U.S. cities. Cities 58:143-151. https://doi. org/10.1016/j.cities.2016.05.018

Park, J., J.H. Kim, D.K. Lee, C.Y. Park, and S.G. Jeong. 2017. The influence of small green space type and structure at the street level on urban heat island mitigation. Urban For. Urban Green. 21:203-212. https://doi.org/10. 1016/j.ufug.2016.12.005

Pearsall, H., S. Lucas, and J. Lenhardt. 2014. The contested nature of vacant land in Philadelphia and approaches for resolving competing objectives for redevelopment. Cities 40(B):163-173. https://doi.org/10.1016/j.cities.20 13.04.008

Scorsone, E. 2011. Long-term crsis and systemic failure: Taking the fiscal stress of america's older cities seriously. Case study: City of Flint, Michigan. Retrieved from https://www.cityofflint.com/wp-content/uploads/Report s/MSUE_FlintStudy2011.pdf

Sohn, W., J.H. Kim, M.H. Li, and R. Brown. 2019. The influence of climate on the effectiveness of low impact development: A systematic review. J. Environ. Manag. 236:365-379. https://doi.org/10.1016/j.jenvman.2018.11.041

South, E.C., B.C. Hohl, M.C. Kondo, J.M. MacDonald, and C.C. Branas. 2018. Effect of greening vacant land on mental health of community-dwelling adults: A cluster randomized trial. JAMA Netw. Open 1(3). https://doi.org/10.1001/jamanetworkopen.2018.0298

Wisely, J. 2016, February 16. Flint residents paid America's highest water rates. Detroit Free Press. Retrieved from https://www.freep.com/story/news/local/michigan/flintwater-crisis/2016/02/16/study-flint-paid-highest-rate-uswater/80461288/ 